\title{
Variability of Hydrological Parameters and Water Balance Components in Small Catchment in Croatia
}

\author{
Lidija Tadić, ${ }^{1}$ Tamara Dadić, ${ }^{1}$ and Marija Leko-Kos ${ }^{2}$ \\ ${ }^{1}$ Faculty of Civil Engineering, University of Osijek, Crkvena 21, 31000 Osijek, Croatia \\ ${ }^{2}$ SIRRAH-PROJEKT, Ribarska 4, 31000 Osijek, Croatia \\ Correspondence should be addressed to Lidija Tadić; ltadic@gfos.hr
}

Received 2 October 2015; Accepted 29 November 2015

Academic Editor: Milan Gocic

Copyright (c) 2016 Lidija Tadić et al. This is an open access article distributed under the Creative Commons Attribution License, which permits unrestricted use, distribution, and reproduction in any medium, provided the original work is properly cited.

\begin{abstract}
Analysis of small catchment area in Croatian lowland with its hydrological characteristics in the period between 1981 and 2014 was carried out in order to define significance of change in hydrological and meteorological parameters (precipitation, air temperatures, and discharges) and water balance components (deep percolation and potential evapotranspiration). There was no significant land use change in the observed period, so all changes in hydrological processes can be considered to be without human impact in the last 35 years. Application of RAPS (Rescaled Adjusted Partial Sums) on all data series distinguished two subperiods with different length but the same behaviour. The first subperiod was a period characterised by the decrease, starting in 1980 and finishing between 1991 and 1995, while the second one was a period characterised by the increase of parameters in all analyses, starting between 1991 and 1995 and finishing in 2001. In comparison to the analysis of climate change impacts per decade, this approach is much more appropriate and gives insight into variations throughout the entire observed period. The most variable but not significant parameters are precipitation and discharges, especially in the second subperiod which has a major impact on occurrence of hydrological hazards such as droughts and floods and makes great pressure and responsibility on water management system.
\end{abstract}

\section{Introduction}

Climate and human induced changes on catchment hydrological processes are major concerns for scientists, water decision-makers, and politicians. Different scenarios of climate change and its impact on water balance directly and on ecological, chemical, and geomorphological processes indirectly are the main issues of many studies in the last ten years all over the world. Most of them were dealing with different climate scenarios and their impact on global ecosystem, water management, or economy. Global modelling with simulating global water cycle and in that context analysing hydrological extremes and water balance components is the most common approach, as Corzo Perez et al. stated [1]. Droughts are global hydrological phenomena found to increase in duration, area, and severity, according to Lloyd-Hughes et al. [2]. But validation of global models had to be done by observations on smaller scale, on the number of catchment areas of different characteristics, as it was studied by Stahl et al. [3],
Gudmundsson et al. [4], and Prudhomme et al. [5]. For example, research of 44 catchments made by Van Loon and Laaha [6] and based on long data series in Austria proved that droughts are strongly governed by combination of climate characteristics, increase of temperature and change of precipitation pattern, and catchment control. One of the most important climate elements is precipitation, strongly affecting water balance and quality of water resources. There are many uncertainties in prediction of precipitation amount, intensity, and seasonal and spatial distribution in the future, presented by De Luis et al. [7], Orlowsky and Seneviratne [8], and Nunes and Lourenço [9]. In the report of IPCC-2007 [10], there is an increase of precipitation in the period 1900-2005 north of the $30^{\circ}$ latitude, but it is also stressed that regional and subregional variabilities are frequent and must be carefully analysed. In Northern Germany, a significant precipitation increase and consequently discharge are expected in the coming decades, starting around 2030 with the assumption that all natural features remain stable, apart from climate [11]. There 
are several scenarios which predict climate change impacts on water resources and water balance components over different regions and throughout all seasons. Spatial distribution of much affected areas is relatively well described, according to authors Blöschl and Sivapalan [12] and Kundzewicz et al. [13]. At the seasonal to interannual timescale, the influence of climate variability on hydrological data (and the occurrence of extreme hydrological events such as floods and droughts) is less recognized. These influences can generate seasonal distortions in the statistical data of hydrological variables, thus threatening the validity of the operational rules applied to water management systems. There is also increasing awareness that the strength of important fluctuations in the global climate may vary at the decadal timescale. Moreover, model studies suggest and observational evidence confirms that an intensified hydrological cycle is likely to be an important consequence of global climate change [14]. However, relationship between physical characteristics and temporary trends of annual precipitation, potential evapotranspiration, and runoff is very important and unique for each catchment area [15]. Future climate scenarios predict higher evapotranspiration rates, lower discharge rates, and groundwater levels. It means that, in the mostly agricultural areas, irrigation rates will increase, but the water resources could be questionable [16]. As a consequence, serious water scarcity could be expected on the regional levels, meso and macro scale [17]. Most researches are oriented to the large river basins (macro scale), but small catchment areas (meso and micro scale) seem to be more vulnerable. By definition of Sivapalan et al. [14], these are fundamental landscape units for the water cycle, sediment, and dissolved geochemical and biogeochemical constituents. As such, they integrate all aspects of the hydrological cycle (surface water, runoff, evapotranspiration, groundwater, etc.) within a defined area that can be studied, quantified, and acted upon. The hydrological processes develop faster; increasing of urbanization and other land uses and land cover change have more significant influence on the landscape and environment. Relationship between soil moisture and temperature and soil moisture and precipitation and their possible modification with climate change can have a tremendous impact on water balance [18]. Huntington [19] wrote that potential acceleration of hydrological cycle under recent and future global warming is of considerable interest in terms of changes and regional variability and extremes. According to the analysis of small catchments made by Tesaŕ et al. [20] and Varis et al. [21], small catchments are very vulnerable from the hydrological point of view. Their size is the main characteristic which defines their hydrological features and water balance in general. Large catchments with areas exceeding $1000 \mathrm{~km}^{2}$ have well defined relationship between the actual discharge in the closing profile and the total precipitation for a given antecedent period. Gradually, it became evident that models conceived in this way are unable to describe the reality of runoff formation from small catchments with areas up to $100 \mathrm{~km}^{2}$. Their topographical characteristics, vegetation cover, shape and slope of the catchment, and density of watercourse network have a strong influence on hydrological and geochemical processes. As a result, soil moisture and water balance patterns are very patchy, leading to large spatial variations in evapotranspiration and stream discharge as stated by Ruch and Harum, [22]. Human activities in the form of settlements, infrastructure, and hydraulic structures also have significant impacts on the small scale, even more pronounced than on a large scale [23]. Besides, small catchments usually have shorter series of data records and level of their certainty is much lower, which also could be one of the reasons why small catchments are less described from the hydrological point of view [24]. Another problem is definition of small catchment; generally, catchment areas smaller than $100 \mathrm{~km}^{2}$ are considered to be small, but there is another approach which defines small catchment as an area with stable and uniform hydrological characteristics and the actual area is not important as much as uniformity of hydrological processes over the catchment area [12].

Most of the previous investigations have been carried out on a macro scale, on the national or regional level. Territory of Croatia belongs to the transitional area between Northern Europe with weak positive trend of annual precipitation amounts in the continental part of the country and drying Mediterranean with more pronounced seasonal trends [25]. Potentially, human induced changes and interaction with natural characteristics of terrain, soil, land cover, and meteorological parameters yield specific and unique hydrological characteristics which might have a great influence on water management. In macro scale, it is very difficult to separate influences induced by human activities from climate change impacts, but in small catchment areas it could be possible. This paper is going to present changes in hydrological parameters on small catchment area in Croatian lowland with no significant human interventions, so all potential changes in hydrological processes must be related to climate change.

\section{Materials and Methods}

2.1. Study Area. Catchment area of Karašica and Vučica Rivers is located in Danube River basin, part of the Drava River catchment, and its location in the Croatian lowland together with meteorological and hydrological stations and groundwater observation wells relevant for the research area is given in Figure 1. It is small catchment with two different parts. The larger part is typical lowland with altitude between 85 and $125 \mathrm{~m}$ a.s.l. (Figure 2(a)). The lowest point is at the mouth of Vučica River into the Drava River. Most of the terrain is higher than the maximum water level of the Drava River, so the area is not affected by high Drava River water levels. The vegetation cover mostly consists of agricultural land, pastures, and forests. Hilly part of the catchment is situated on the southern part, with the altitudes between 125 and $953 \mathrm{~m}$ a.s.l. Hilly part is covered by forest, orchards, and vineyards and takes about one-third of the total area. There are many smaller brooks that during high water levels contribute to the discharge of major rivers and cause floods. The whole catchment area has very dense network of natural and artificial watercourses constructed in the last 150 years. Their main purpose was, and still is, flood protection and land drainage studied by Tadić et al. [26]. 
TABLE 1: Characteristics of meteorological and hydrological stations.

\begin{tabular}{|c|c|c|c|c|}
\hline \multicolumn{5}{|c|}{ Meteorological stations } \\
\hline Name & \multicolumn{2}{|r|}{ Elevation (m a.s.l.) } & \multicolumn{2}{|c|}{ Period of observations } \\
\hline Donji Miholjac & \multicolumn{2}{|r|}{97.00} & \multicolumn{2}{|c|}{$1981-2014$} \\
\hline Valpovo & \multicolumn{2}{|r|}{91.00} & \multicolumn{2}{|c|}{ 1981-2014 } \\
\hline Našice & \multicolumn{2}{|r|}{144.00} & \multicolumn{2}{|c|}{ 1981-2014 } \\
\hline Slatina & \multicolumn{2}{|r|}{144.00} & \multicolumn{2}{|c|}{ 1981-2014 } \\
\hline Orahovica & \multicolumn{2}{|r|}{180.00} & \multicolumn{2}{|c|}{$1991-2014^{*}$} \\
\hline \multicolumn{5}{|c|}{ Hydrological stations } \\
\hline River/station & Location & Distance from the mouth $(\mathrm{km})$ & Catchment area $\left(\mathrm{km}^{2}\right)$ & Period of observation \\
\hline Karašica/Kapelna & $45^{\circ} 42^{\prime} 35^{\prime \prime}$ & $33+010$ & 388.8 & $1987-2012$ \\
\hline Vučica/Orahovica & $45^{\circ} 32^{\prime} 29^{\prime \prime}$ & $74+950$ & 42.6 & 1987-2012 \\
\hline Vučica/Beničanci & $45^{\circ} 36^{\prime} 47^{\prime \prime}$ & $48+500$ & 750.5 & $1987-2012$ \\
\hline
\end{tabular}

* Only precipitation data.

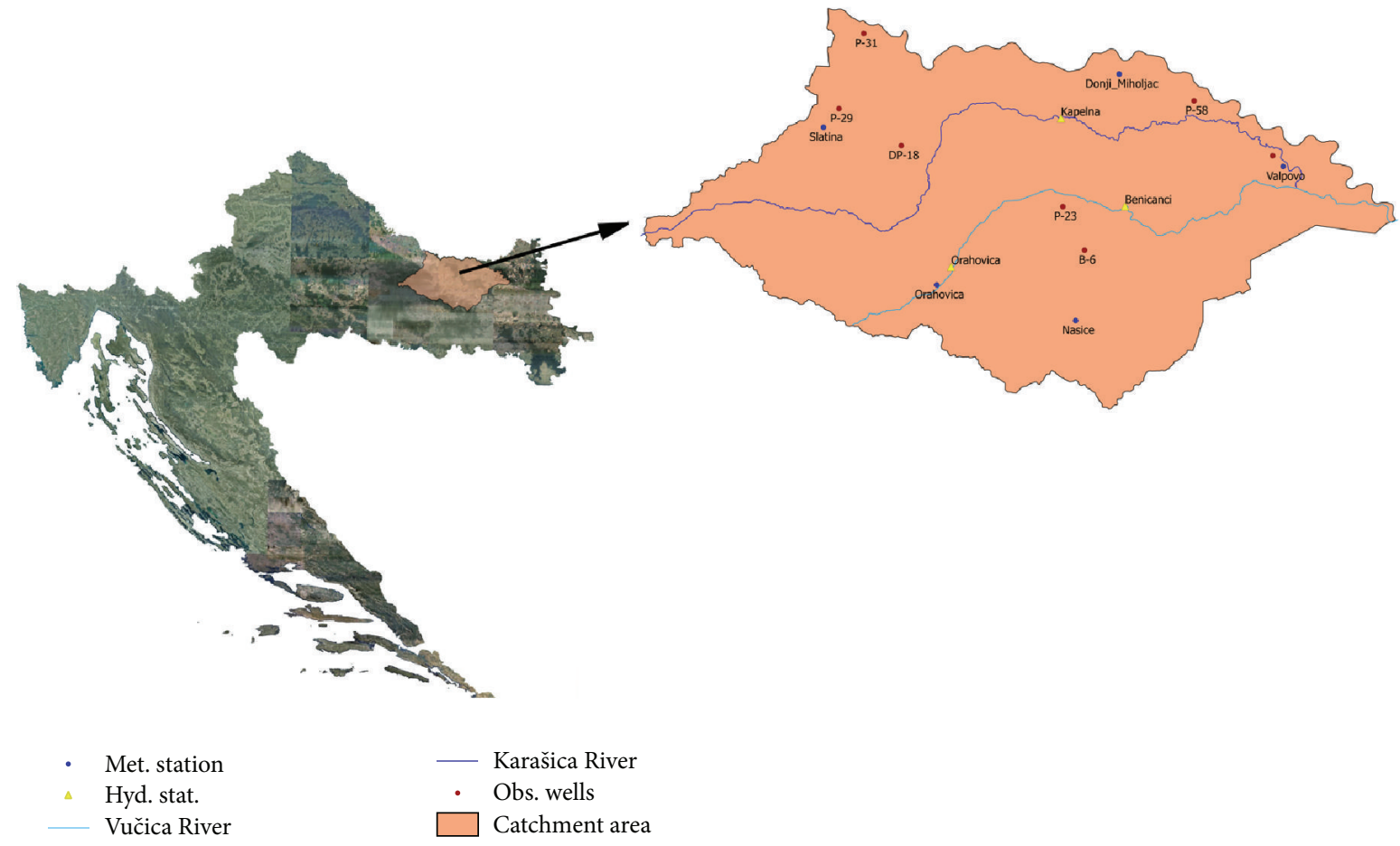

FIGURE 1: Catchment area with meteorological and hydrological stations.

2.2. Hydrological and Meteorological Characteristics. Data used in the analysis includes monthly and annual precipitation, mean monthly and mean annual precipitation, monthly groundwater levels, and monthly discharges of Karašica and Vučica Rivers. In Table 1, the main characteristics of meteorological and hydrological stations are given.

The catchment of Karašica and Vučica Rivers can be considered as very stable area according to land use change which is important for further analysis; therefore, all other changes in hydrological parameters and processes in the observed period are consequence of climate change. Changes in land use on catchment area were analysed based on Corine Land Cover data which is digital database including changes in land cover and land use for the Republic of
Croatia in the period from 1981 to 2012 (Figure 2(b)). There are five different datasets between 1980 and 2012. In this period, change appeared on 13.000 ha but most of it was from unirrigated arable land to irrigable land and from areas of natural vegetation to forest. In total, about $16 \%$ of the catchment area land cover has changed, but without significance [27]. It is very important because land use change has significant influence on hydrological processes. For example, Wang et al. [28] and Amirabadizadeh et al. [29] investigated a major influence of land use change, urbanization, and industrialization on water balance change. Data series of monthly and annual precipitation amounts and the mean monthly and annual air temperature are observed on the five meteorological stations in the period between 1981 

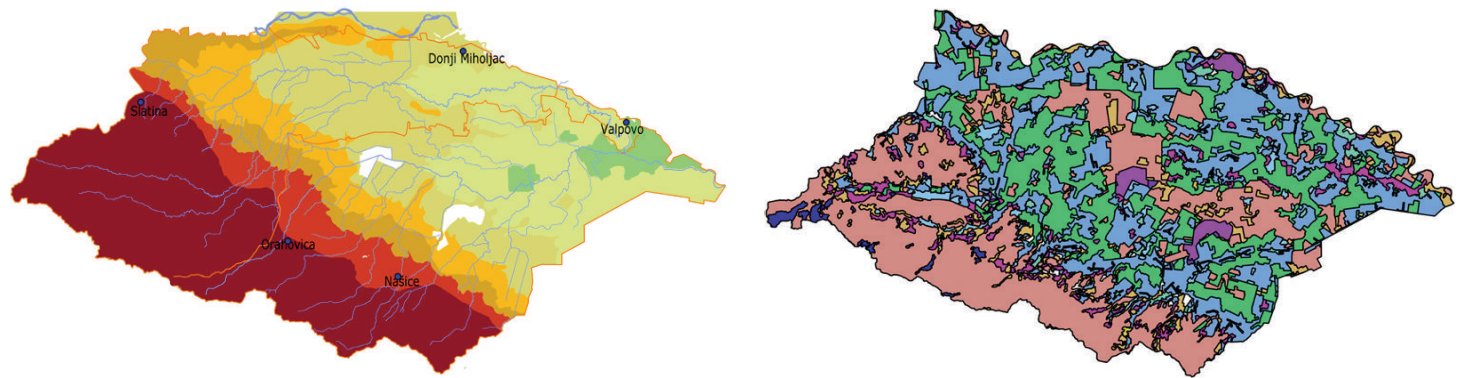

- Met. station Altitude (m a.s.l.)

\begin{tabular}{|l|l|}
\hline $85-90$ & $105-110$ \\
$90-95$ & Transitional hilly part \\
$95-100$ & Hilly part \\
\hline
\end{tabular}

(a)

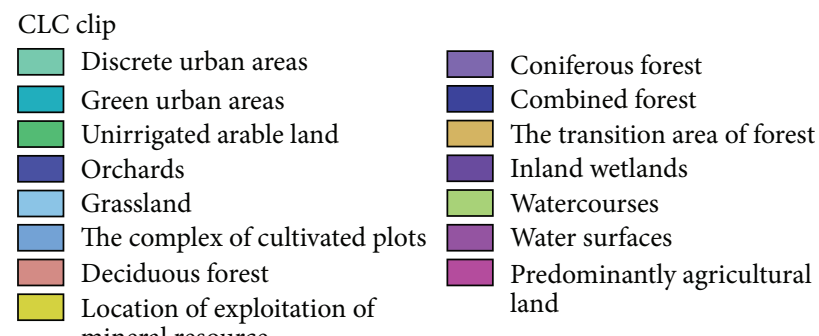

(b)
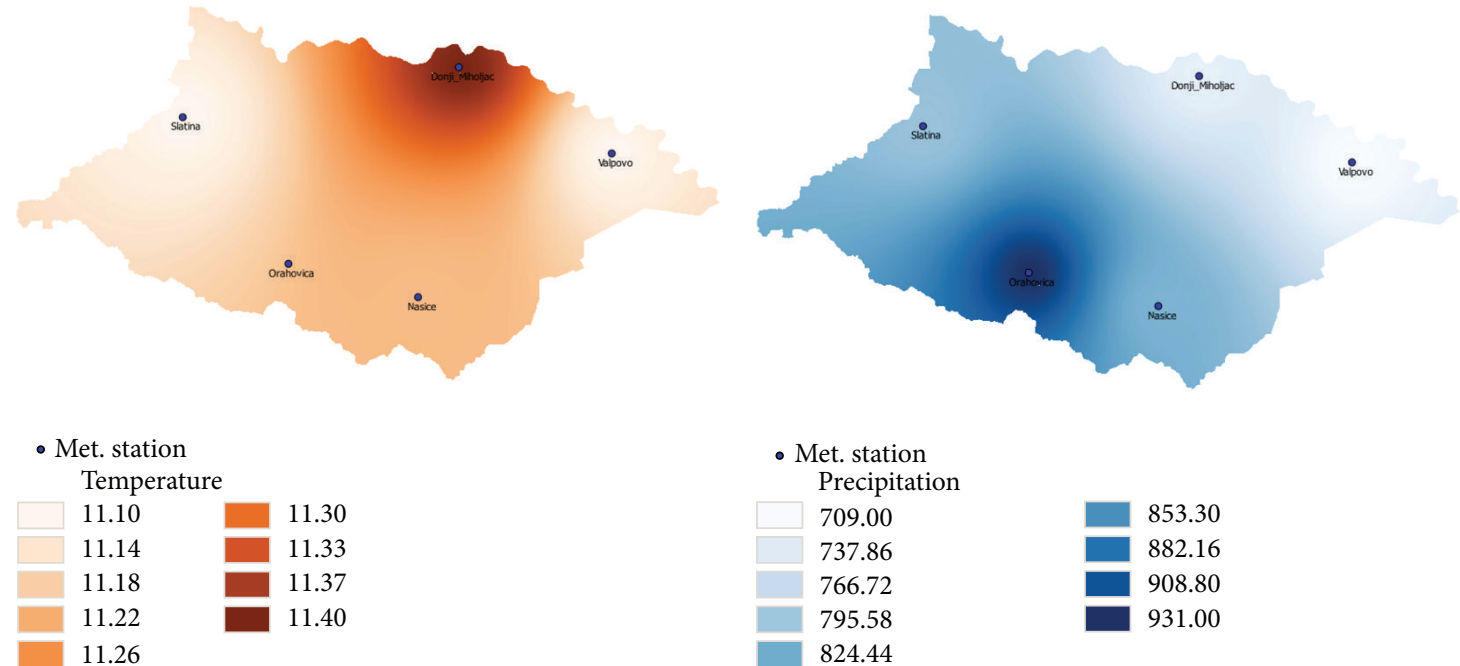

(c)
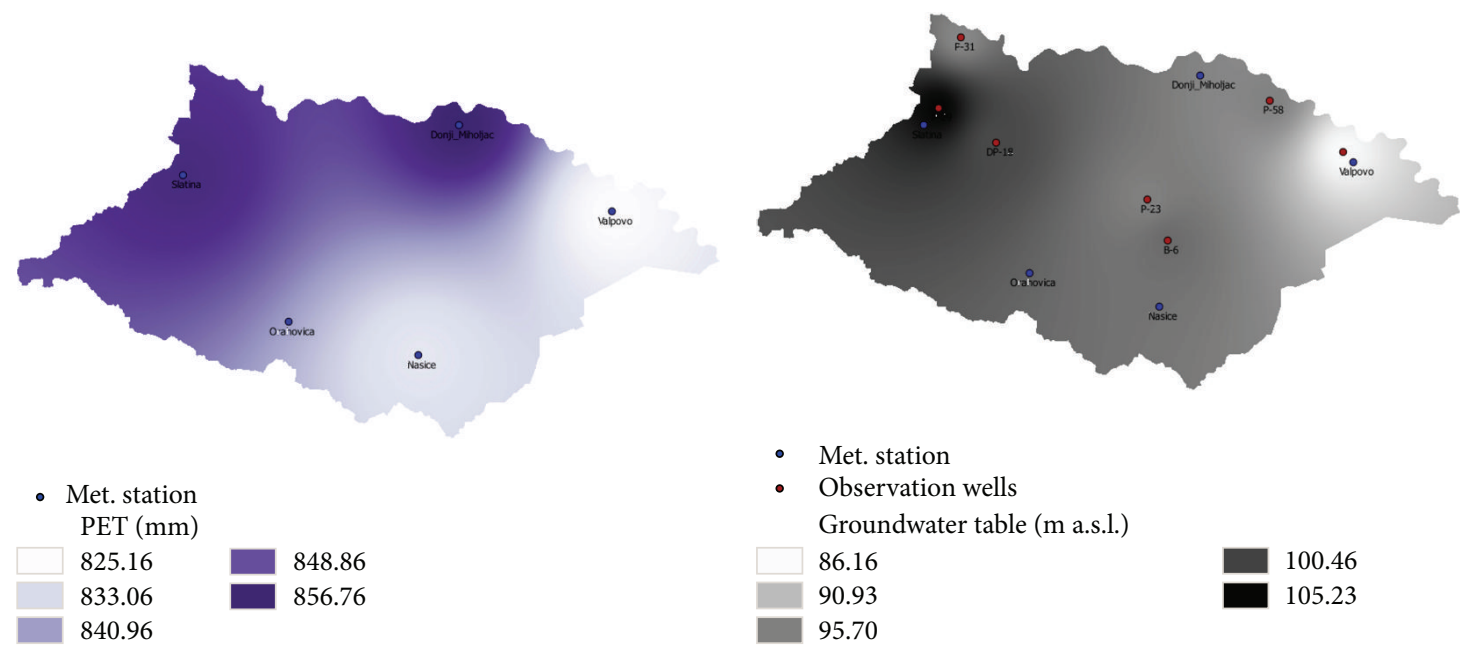

(e)

(f)

Figure 2: (a) Altitude map of the catchment area, (b) land use map, (c) mean air temperature distribution, (d) annual precipitation distribution, (e) annual potential evapotranspiration distribution, and (f) mean groundwater level. 
and 2014. Annual precipitation varies between $710 \mathrm{~mm}$ in the lower part and $816 \mathrm{~mm}$ in the hilly part of the catchment (Figure 2(d)). Mean annual groundwater level is presented in Figure 2(f), and it is approximately $3.0 \mathrm{~m}$ below soil surface. Figures 2(c) and 2(e) present mean air temperature distribution and mean annual potential evapotranspiration. Potential evapotranspiration was calculated by Hargreaves and Samani (HS) [30] equation:

$$
\mathrm{ETo}=0.0135 \operatorname{Rs}(T+17.8),
$$

where Rs is expressed in units of water evaporation in $\mathrm{mm} /$ day and $T$ in ${ }^{\circ} \mathrm{C}$. According to Trajković [31] who studied the HS equation in seven locations in continental Europe, including Croatia, with different altitudes (42-433 m a.s.l.) with $\mathrm{RH}$ ranging from 55 to $71 \%$, it is considered to be applicable for the study area.

2.3. Methodology with the Description of RAPS and SPI. In order to demonstrate trends in hydrological parameters and water balance components, RAPS (Rescaled Adjusted Partial Sums) method was used. Random changes, errors, and variability in the analysed time series were overcome with this method. The observed period with this method is divided into several subperiods, based on calculated $F$-test and $t$-test at level $p<0.05$. RAPS are calculated by expression $[32,33]$

$$
\operatorname{RAPS}_{k}=\sum_{t=1}^{k} \frac{Y_{t}-\bar{Y}}{S_{y}},
$$

where $\bar{Y}$ is the mean value of observed time series; $S$ is the standard deviation; $Y_{t}$ is the observed parameter (in this case maximum annual discharge and water level in year $t) ; k$ is the total number of observed years.

Variations of analysed parameters are calculated as a ratio of standard deviation and average value for subject period.

Drought analysis was made by Standardised Precipitation Index (SPI), the method most frequently used in all parts of the world, regardless of climatic or topographical features. The basic advantage of this method lies in the fact that it necessitates only a set of precipitation data for a longer period of time (30 or more years) and that it can be used at various timescales, the most frequent ones being $1,3,6,12$, and 24 months. The SPI has defined limit values dependent on the relative frequency; according to McKee et al. [34], a positive SPI points to a greater quantity of precipitation with respect to the mean multiyear value, while a negative SPI is an indication of lower precipitation compared to mean value.

\section{Results and Discussion}

In Croatia, which is in the transitional zone, precipitation increase can be expected in the future (Perčec Tadić et al. [35]), but in the observed period (1981-2014) there is no increasing trend in annual precipitation according to the records from five meteorological stations (Figure 3). Annual precipitation and mean air temperature were analysed on five meteorological stations in the period between 1981 and 2014 which is presented in Figure 3.

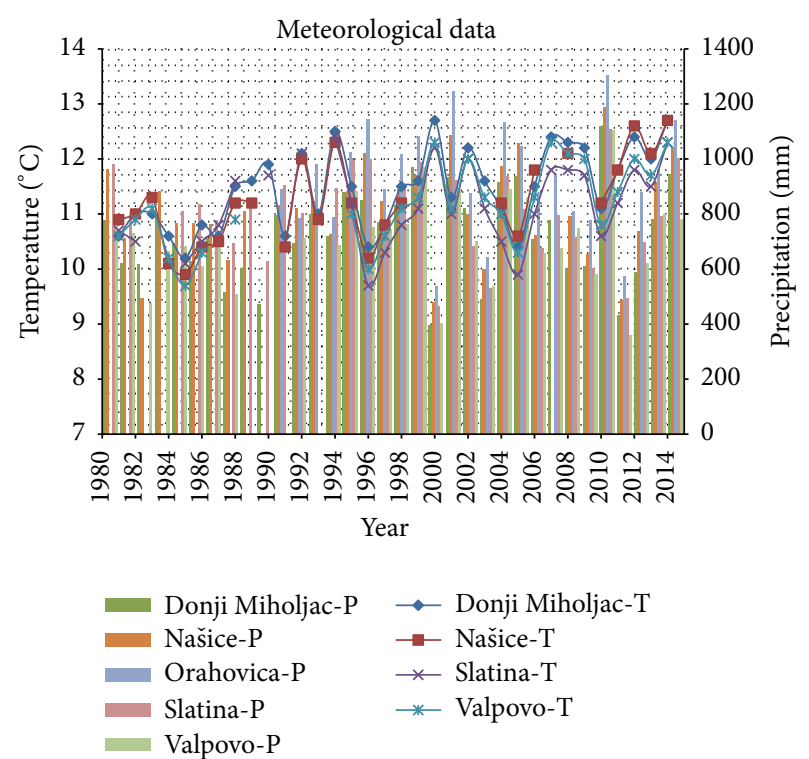

FIgURE 3: Annual precipitation and mean air temperature.

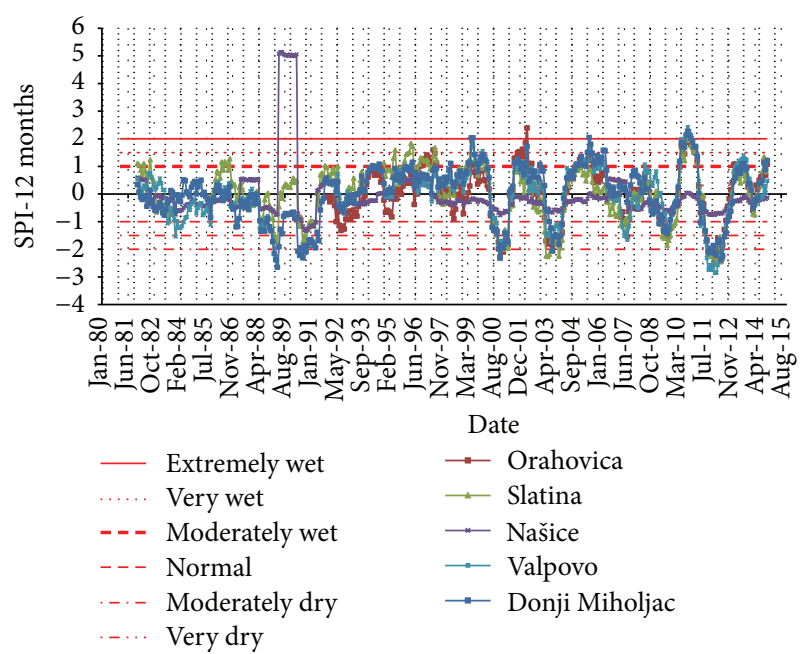

FIGURE 4: Mean annual SPI for all meteorological stations.

The study area is characterized by extreme hydrological events, droughts, and floods which occur frequently causing great damage. Previous research proved that the most severe droughts have occurred in 2000, 2003, and 2011 in the continental part of Croatia [36].

Annual SPI values did not show any trend $\left(R^{2}=\right.$ 0.0004-0.0032) during the observed period which can be seen in Figure 4, but greater variability can be recognized in the beginning of the 21st century.

Hydrographs of characteristic annual discharges of Karašica and Vučica Rivers are presented in Figure 5. There is no significant trend in maximum, minimum, or mean annual discharges in the period 1981-2012 $\left(R^{2}=0.0008-0.0115\right)$.

Floods are another type of extreme hydrological events which are more frequent in the last decades. Similar to the droughts, they also cause great damage to water management, 


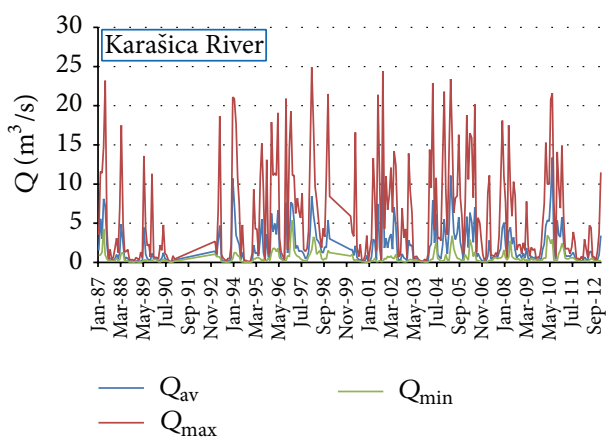

(a)

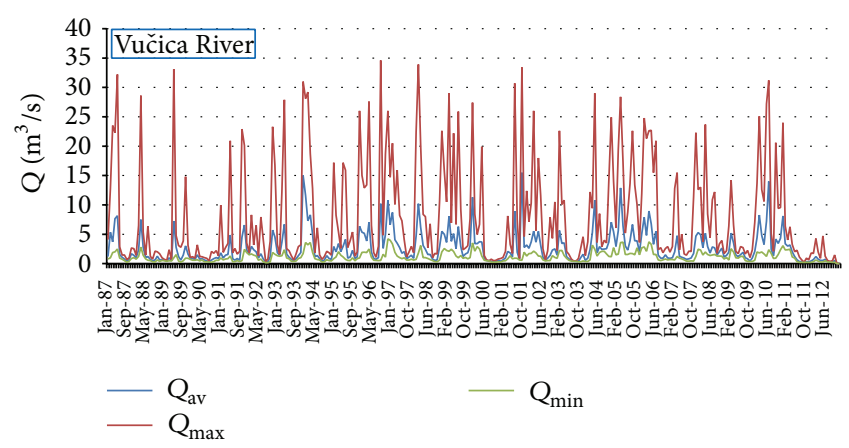

(b)

FIgURE 5: Characteristic discharges of the Karašica River (a) and the Vučica River (b).

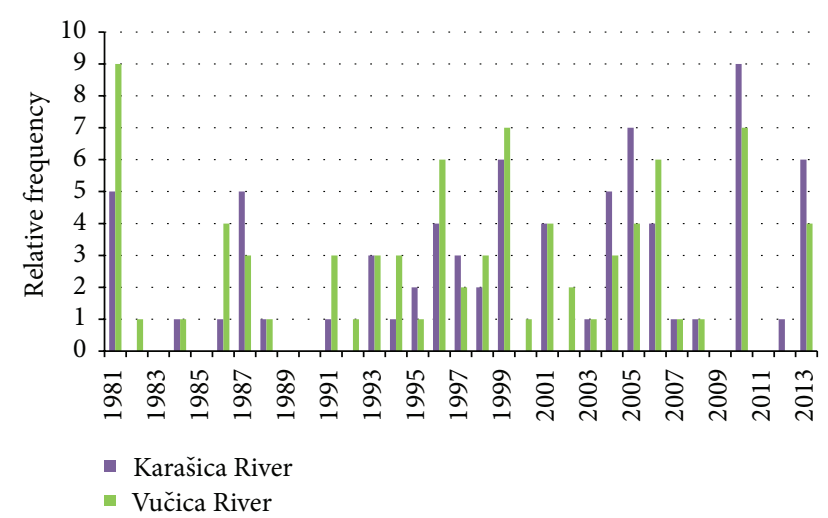

Figure 6: Flood events on the Karašica and Vučica Rivers in the period 1981-2012.

agriculture, and ecosystems. In the observed period between 1981 and 2012, floods have occurred several times (Figure 6).

Spatial distribution of annual groundwater level is presented in Figure 2(b).

Previously described hydrological and meteorological parameters and water balance components did not show any specific trend during the observed period, but there are visible variations in the last decade. Those variations were analysed in more detail in order to achieve a better understanding of hydrological processes in the catchment.

3.1. Precipitation and Air Temperatures. As it was presented previously, there is no increasing precipitation trend in the study area. The application of RAPS on the monthly precipitation data distinguished subperiods with various lengths. The first subperiod, 11 years long, is characterized by decrease of precipitation ending between April 1991 in lower part of the catchment and September 1992 in the hilly part. In the second subperiod, monthly precipitation is increasing (Figure 7(a)). Only in Slatina station are there 3 subperiods; the third one started in December 1999.

The variability of precipitation is one of the predictions of climate change [37] and in the analysed area it is obvious in the observed period even if it is relatively short. Large precipitation variability is beside the amount, main cause of vulnerability to droughts and floods, with a tremendous impact on agriculture, ecosystem, and water management. However, RAPS method applied on annual air temperatures shows more significant change during the whole observed period and subperiods as well. In two meteorological stations, the first subperiod lasted until 1997 and 1998, respectively, with decreasing air temperature trend and the second subperiod with an increasing trend. On the station Našice the breaking point is year 2005, and on meteorological station Slatina there are not any significant changes in the air temperature (Figure 7(b)). These results prove previous conclusions about an average increase of $0.84^{\circ} \mathrm{C}$ in the period of 50 years or longer obtained on 26 stations in Croatia reached by Bonacci [38].

Calculation of coefficients of variation (CV) of precipitation for these two subperiods and testing of their significance show variations but without statistical significance (0.560.62 in the second subperiod, while in the first period significance was between 0.62 and 0.64). Difference of mean air temperatures between the recognized two subperiods is about $1^{\circ} \mathrm{C}$. Comparing to the precipitation variability, air temperature coefficients of variation are much smaller and their values are between 0.043 and 0.058 .

The same procedure was applied on discharges, groundwater levels, and potential evapotranspiration. RAPS method distinguished two subperiods in each data series but with different duration. Research of Rasouli et al. [39] proved high sensitivity of stream flow to changes in the whole range of hydrological processes in the basin, with particular regard to precipitation. Besides, in relation to extreme fluctuations in precipitation and impact of natural characteristics as far as human activities, water management practice is becoming complex and unreliable. Hydraulic structures are constructed in order to fulfil their purposes including flood protection, irrigation water uptake, and drainage, and their operation in the different conditions makes them unreliable [13]. Their possible adaptation to present and even more significant changes in the future has a lot of uncertainties because there is no accurate projection of future hydrological processes. Most of the research obtained opposite trends of discharges, strongly influenced by natural characteristics of the catchment and their significant variability [40]. 


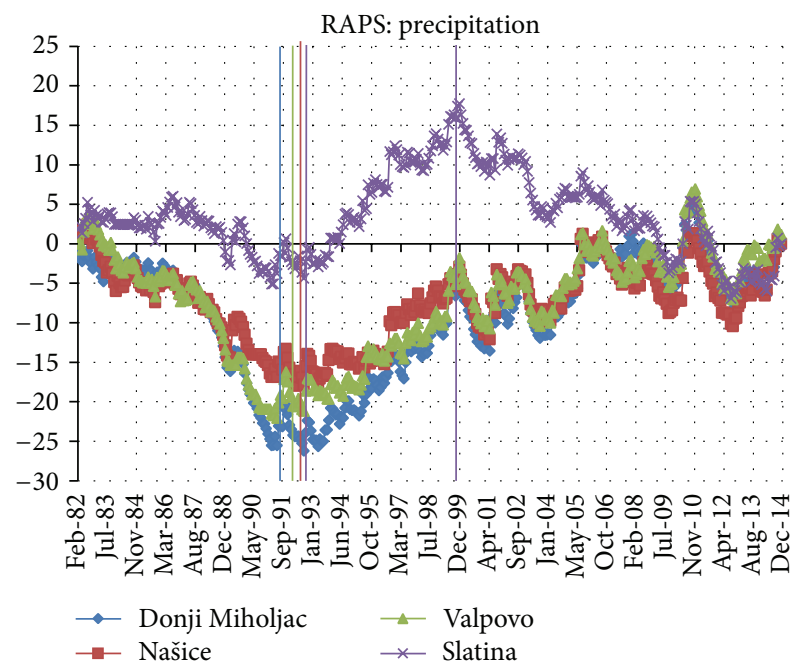

(a)

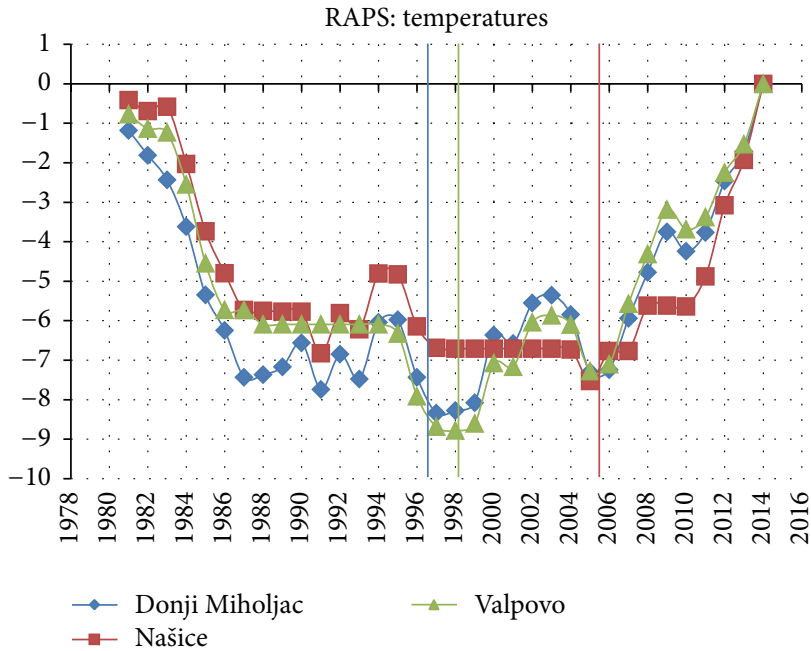

(b)

FIGURE 7: (a) RAPS of monthly precipitation data and (b) RAPS of mean annual air temperature data.

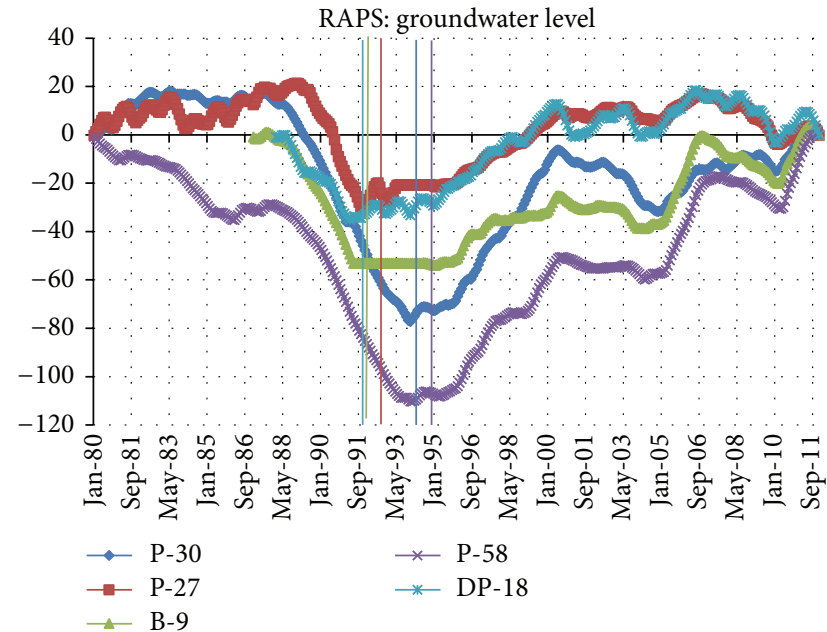

(a)

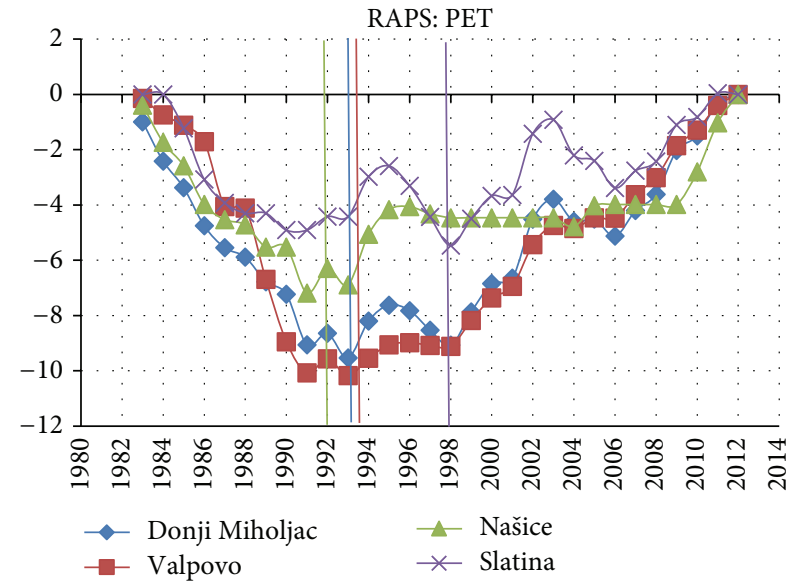

(b)

FIGURE 8: (a) RAPS of mean monthly groundwater levels and (b) RAPS of mean annual potential evapotranspiration.

Results obtained in this research confirm previous statement, but subperiods of decreasing and increasing discharges have a delay of 4-5 years comparing to the precipitation, and the coefficients of variations are not significant.

Annual groundwater levels have also two subperiods, the first period of decrease (1991-1993) and the second subperiod of increase of groundwater level. The results of previous Croatian researches on water balance components of much larger areas and longer data series periods (19001995) made by Zaninović and Gajić-Čapka [41] recognized a significant increase in potential evapotranspiration and decrease in runoff and soil water content and predicted further development of the analysed processes in the next century. The proposed analysis of small catchment water balance did not completely prove the results. Changes in potential evapotranspiration are present but not significant.
Figure 8 shows application of RAPS method on both, groundwater level and potential evapotranspiration. The first subperiod shows decreasing trend of groundwater level (breaking year is between 1991 and 1995) and the second subperiod of increasing groundwater level. Potential evapotranspiration has a similar behaviour with breaking year between 1991 and 1994, and for one station it is 1998.

All data series show two subperiods with different duration. Decreasing subperiods finish between 1991 (for precipitation and groundwater levels) and 1997 (for air temperature and discharges). They are followed by increasing periods (Figure 9(a)). Different durations of subperiods distinguished by RAPS are partially related to characteristics of catchment area itself. Particularly, trends in runoff processes show a delay of few years. Usually, it is neglected in the trend analysis of climate change impacts. Also, as a complex hydrological 


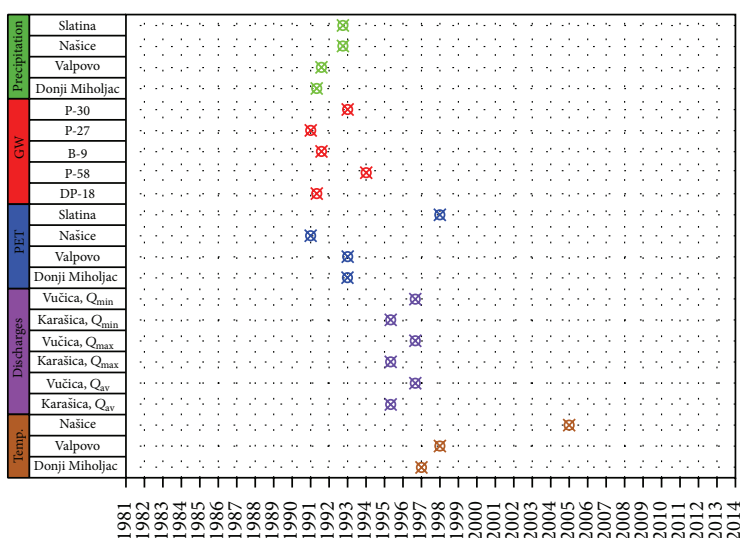

(a)

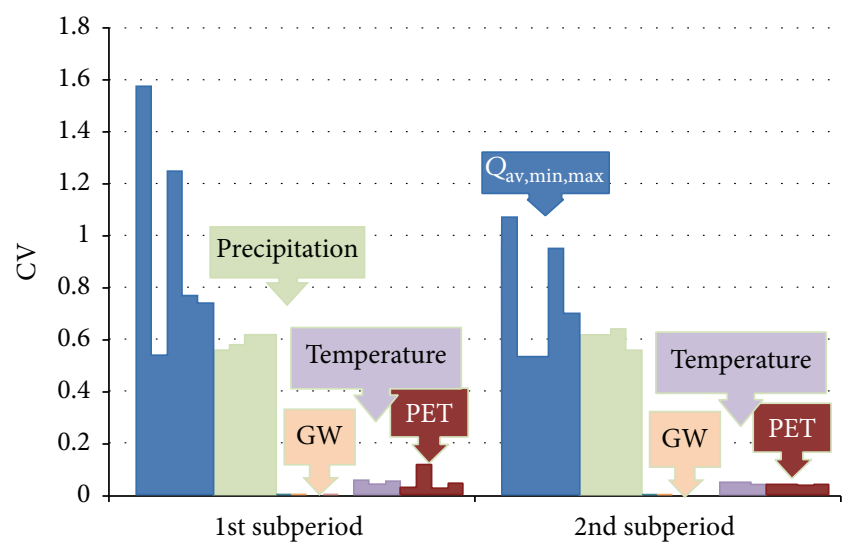

(b)

FIGURE 9: (a) Duration of subperiods distinguished by RAPS and (b) coefficients of variation (CV) of analysed parameters.

process, depending on many parameters, a large variability of characteristic discharges is not surprising. The least variable parameters are air temperatures, potential evapotranspiration, and groundwater levels. There are no statistical differences in significance of $\mathrm{CV}$ in the two subperiods (Figure 9(b)).

\section{Conclusions}

Knowledge of meteorological and hydrological parameters as a driving force of water balance components and their temporal and spatial distribution are essential for water management practice. There are many scenarios of precipitation and air temperature change in the future, but all of them have to be tested on a certain basin with specific geomorphological, hydrological, and vegetation characteristics, and so forth. Each river basin is unique, and small catchment areas especially show significant dependence on shape, slope, land use, and other features, including human structures.

Catchment area of Karašica and Vučica Rivers in Croatia had no significant change in land use since 1980 and all obtained variabilities that occurred in the last period can be considered as a consequence of change in hydrological parameters and processes. Previous research in the area much larger than this study area indicated increase of precipitation, air temperatures, and potential evapotranspiration and decrease of other water balance components, first of all runoff. They are usually given per decade or longer period. This analysis shows opposite results. All analysed parameters in the period of 35 years have two subperiods of different duration related to their hydrological development. The first one is period of decrease, and the second one is period of increase of all parameters, but with time delay of several years, especially in discharges. Also, variability of hydrological parameters is increasing, but without significance. The most variable are discharges and precipitation with consequent occurrence of droughts and floods which make this area and its water management system more vulnerable. Small catchment areas are the basic and unique units of water management, so it is very important to analyse their natural characteristics and processes to be able to cope with water scarcity or sufficiency in the best way.

\section{Conflict of Interests}

The authors declare that there is no conflict of interests regarding the publication of this paper.

\section{References}

[1] G. A. Corzo Perez, M. H. J. van Huijgevoort, F. Voß, and H. A. J. van Lanen, "On the spatio-temporal analysis of hydrological droughts from global hydrological models," Hydrology and Earth System Sciences, vol. 15, no. 9, pp. 2963-2978, 2011.

[2] B. Lloyd-Hughes, L. C. Shaffrey, P. L. Vidale, and N. W. Arnell, "An evaluation of the spatiotemporal structure of largescale European drought within the HiGEM climate model," International Journal of Climatology, vol. 33, no. 8, pp. 20242035, 2013.

[3] K. Stahl, H. Hisdal, J. Hannaford et al., "Streamflow trends in Europe: evidence from a dataset of near-natural catchments," Hydrology and Earth System Sciences, vol. 14, no. 12, pp. 23672382, 2010.

[4] L. Gudmundsson, L. M. Tallaksen, K. Stahl et al., "Comparing large-scale hydrological model simulations to observed runoff percentiles in Europe," Journal of Hydrometeorology, vol. 13, no. 2, pp. 604-620, 2012.

[5] C. Prudhomme, S. Parry, J. Hannaford, D. B. Clark, S. Hagemann, and F. Voss, "How well do large-scale models reproduce regional hydrological extremes in Europe?” Journal of Hydrometeorology, vol. 12, no. 6, pp. 1181-1204, 2011.

[6] A. F. Van Loon and G. Laaha, "Hydrological drought severity explained by climate and catchment characteristics," Journal of Hydrology, vol. 526, pp. 3-14, 2015.

[7] M. De Luis, J. C. González-Hidalgo, M. Brunetti, and L. A. Longares, "Precipitation concentration changes in Spain 19462005," Natural Hazards and Earth System Science, vol. 11, no. 5, pp. 1259-1265, 2011.

[8] B. Orlowsky and S. I. Seneviratne, "Global changes in extreme events: regional and seasonal dimension," Climatic Change, vol. 110, no. 3-4, pp. 669-696, 2012. 
[9] A. N. Nunes and L. Lourenço, "Precipitation variability in Portugal from 1960-2011," Journal of Geographical Sciences, vol. 25, no. 7, pp. 784-800, 2015.

[10] S. D. Solomon, D. Qin, M. Manning et al., Eds., Climate Change 2007: The Physical Science Basis, Cambridge University Press, New York, NY, USA, 2007.

[11] D.-I. Müller-Wohlfeil, G. Bürger, and W. Lahmer, "Response of a river catchment to climatic change: application of expanded downscaling to Northern Germany," Climatic Change, vol. 47, no. 1, pp. 61-89, 2000.

[12] G. Blöschl and M. Sivapalan, "Process controls on regional flood frequency: coefficient of variation and basin scale," Water Resources Research, vol. 33, no. 12, pp. 2967-2980, 1997.

[13] Z. W. Kundzewicz, L. J. Mata, N. W. Arnell et al., “The implications of projected climate change for freshwater resources and their management," Hydrological Sciences Journal, vol. 53, no. 1, pp. 3-10, 2008.

[14] M. Sivapalan, K. Takeuchi, S. W. Franks et al., "IAHS Decade on Predictions in Ungauged Basins (PUB), 2003-2012: shaping an exciting future for the hydrological sciences," Hydrological Sciences Journal, vol. 48, no. 6, pp. 857-880, 2003.

[15] D. A. Post and A. J. Jakeman, "Relationships between catchment attributes and hydrological response characteristics in small Australian mountain ash catchments," Hydrological Processes, vol. 10, no. 6, pp. 877-892, 1996.

[16] A. Visser, J. Kroes, M. T. H. Van Vliet, S. Blenkinsop, H. J. Fowler, and H. P. Broers, "Climate change impacts on the leaching of a heavy metal contamination in a small lowland catchment," Journal of Contaminant Hydrology, vol. 127, no. 14, pp. 47-64, 2012.

[17] G. Leng, M. Huang, Q. Tang, and L. R. Leung, "A modeling study of irrigation effects on global surface water and groundwater resources under a changing climate," Journal of Advances in Modeling Earth Systems, vol. 7, no. 3, pp. 1285-1304, 2015.

[18] S. I. Seneviratne, T. Corti, E. L. Davin et al., "Investigating soil moisture-climate interactions in a changing climate: a review," Earth-Science Reviews, vol. 99, no. 3-4, pp. 125-161, 2010.

[19] T. G. Huntington, "Evidence for intensification of the global water cycle: review and synthesis," Journal of Hydrology, vol. 319, no. 1-4, pp. 83-95, 2006.

[20] M. Tesaŕ, M. Šír, and L. Lichner, "Runoff formation in a small catchment," in Proceedings of the 9th Conference of the European Network of Experimental and Representative Basins (ERB '02), pp. 7-12, Demänovská Dolina, Slovakia, September 2002.

[21] O. Varis, T. Kajander, and R. Lemmelä, "Climate and water: from climate models to water resources management and vice versa," Climatic Change, vol. 66, no. 3, pp. 321-344, 2004.

[22] C. A. Ruch and T. Harum, "Water balance components for forest and meadow land use systems in a crystalline catchment," in Proceedings of the 9th Conference of the European Network of Experimental and Representative Basins (ERB '02), pp. 26-32, Demänovská Dolina, Slovakia, September 2002.

[23] B. Moldan and J. Černy, "Biogeochemistry of small catchments: a tool for environmental research," Environmental Science and Pollution Research, vol. 1, no. 4, pp. 284-285, 1994.

[24] V. U. Smakhtin, "Low flow hydrology: a review," Journal of Hydrology, vol. 240, no. 3-4, pp. 147-186, 2001.

[25] M. Gajić-Čapka, K. Cindrić, and Z. Pasarić, “Trends in precipitation indices in Croatia 1961-2010," Theoretical and Applied Climatology, vol. 121, no. 1-2, pp. 167-177, 2015.
[26] L. Tadić, Z. Tadić, I. Crnčan, and J. Korov, "Analysis of flood frequency on the area of Drava river basin," in Proceedings of the 21st Conference of Danube Countries on the Hydrological Forecasting and Hydrological Bases of Water Management (Proceedings on CD), Bucharest, Romania, September 2002.

[27] T. Dadić and L. Tadić, "Climate and land use changes impacts on small catchment areas," in Proceedings of the 14th Interational Symposium Water Management and Hydraulic Engineering, pp. 171-180, Brno, Czech Republic, September 2015.

[28] W. Wang, Q. Shao, T. Yang et al., "Quantitative assessment of the impact of climate variability and human activities on runoff changes: a case study in four catchments of the Haihe River basin, China," Hydrological Processes, vol. 27, no. 8, pp. 1158-1174, 2013.

[29] M. Amirabadizadeh, Y. F. Huang, and T. S. Lee, "Recent trends in temperature and precipitation in the Langat River basin, Malaysia," Advances in Meteorology, vol. 2015, Article ID 579437, 16 pages, 2015.

[30] G. H. Hargreaves and Z. A. Samani, "Estimating potential evapotranspiration," Journal of the Irrigation and Drainage Division, vol. 108, no. 3, pp. 225-230, 1982.

[31] S. Trajković, "Hargreaves versus Penman-Monteith under humid conditions," Journal of Irrigation and Drainage Engineering, vol. 133, no. 1, pp. 38-42, 2007.

[32] J. Garbrecht and G. P. Fernandez, "Visualization of trends and fluctuations in climatic records," Water Resources Bulletin, vol. 30, no. 2, pp. 297-306, 1994.

[33] O. Bonacci, D. Trninić, and T. Roje-Bonacci, "Analysis of the water temperature regime of the Danube and its tributaries in Croatia," Hydrological Processes, vol. 22, no. 7, pp. 1014-1021, 2008.

[34] T. B. McKee, N. J. Doeskin, and J. Kleist, "Drought monitoring with multiple time scales," in Proceedings of the 9th Conference on Applied Climatology, pp. 179-184, American Meteorological Society, Dallas, Tex, USA, January 1995.

[35] M. Perčec Tadić, M. Gajić-Čapka, K. Zaninović, and K. Cindrić, "Drought vulnerability in Croatia," Agriculturae Conspectus Scientificus, vol. 79, no. 1, pp. 31-38, 2014.

[36] L. Tadić, T. Dadić, and M. Bosak, "Comparison of different drought assessment methods in continental Croatia," Gradevinar, vol. 67, no. 1, pp. 11-22, 2015.

[37] B. Nijssen, G. M. O’Donnell, A. F. Hamlet, and D. P. Lettenmaier, "Hydrologic sensitivity of global rivers to climate change," Climatic Change, vol. 50, no. 1-2, pp. 143-175, 2001.

[38] O. Bonacci, "Analiza nizova srednjih godišnjih temperatura zraka u Hrvatskoj," Građevinar, vol. 62, no. 9, pp. 781-791, 2010.

[39] K. Rasouli, J. W. Pomeroy, J. R. Janowicz, S. K. Carey, and T. J. Williams, "Hydrological sensitivity of a northern mountain basin to climate change," Hydrological Processes, vol. 28, no. 14, pp. 4191-4208, 2014.

[40] H. Hisdal, K. Stahl, L. M. Tallaksen, and S. Demuth, "Have streamflow droughts in Europe become more severe or frequent?" International Journal of Climatology, vol. 21, no. 3, pp. 317-333, 2001.

[41] K. Zaninović and M. Gajić-Čapka, "Changes in components of the water balance in the Croatian lowlands," Theoretical and Applied Climatology, vol. 65, no. 1-2, pp. 111-117, 2000. 

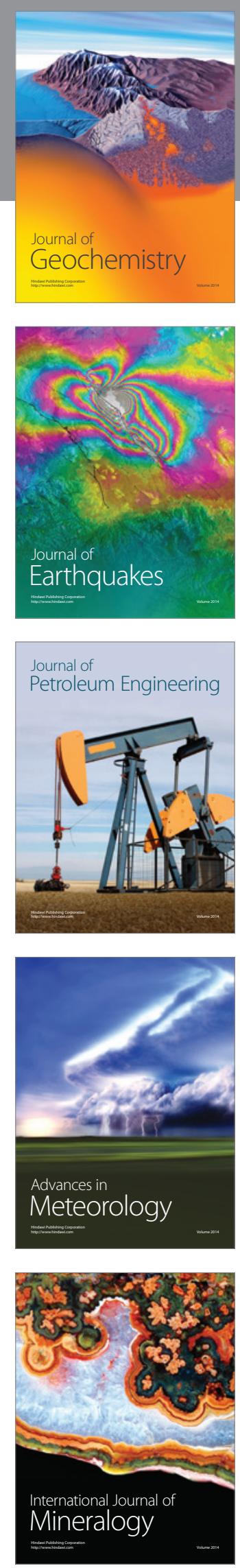
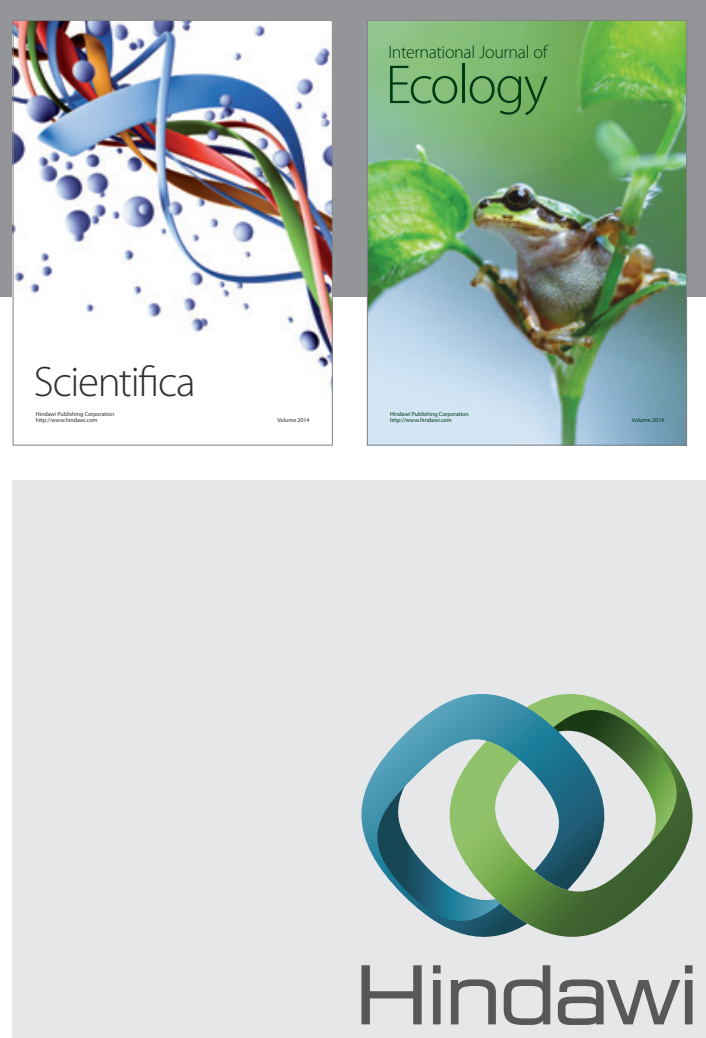

Submit your manuscripts at

http://www.hindawi.com
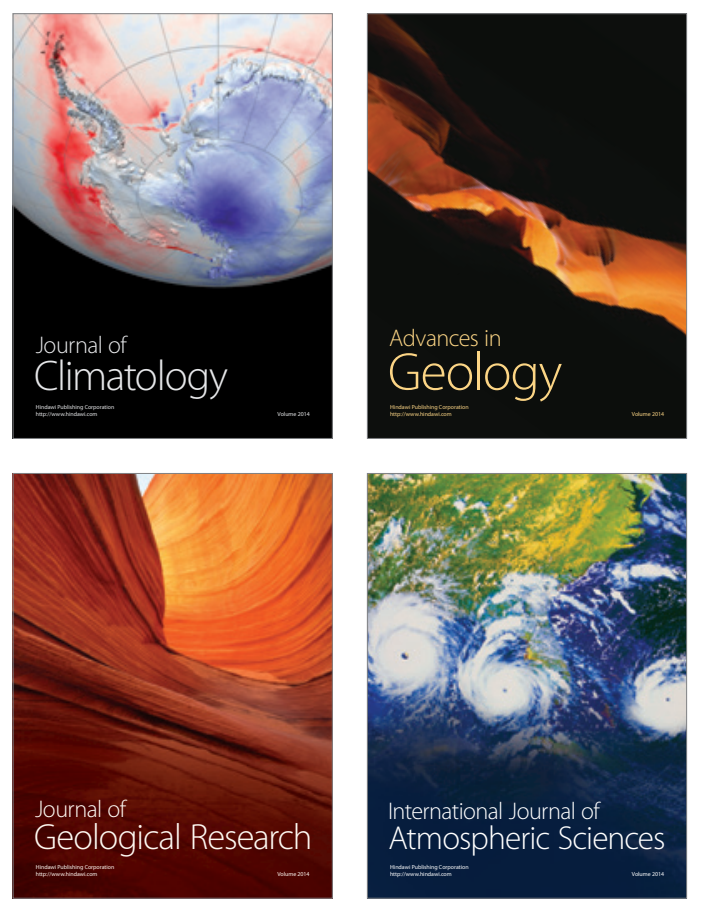

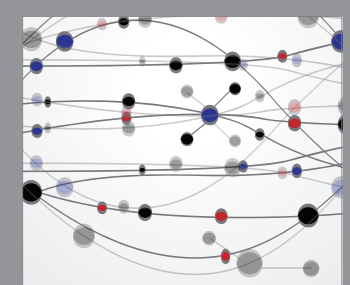

The Scientific

\section{World Journal}
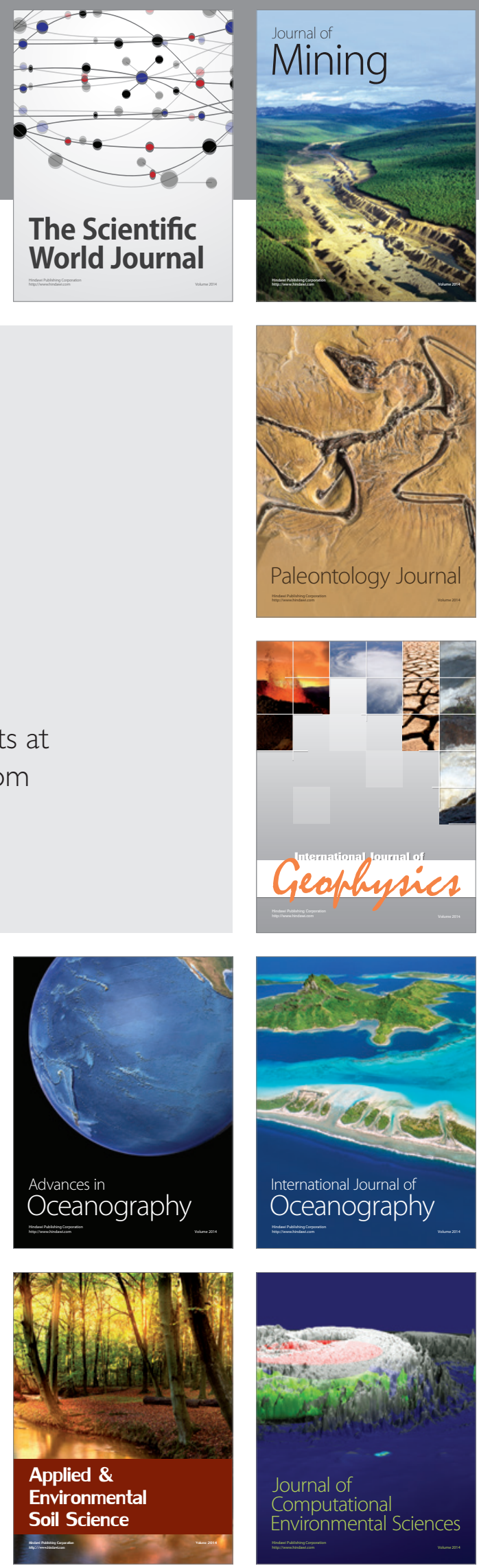